\title{
Maternal smoking during pregnancy and subcutaneous fat mass in early childhood. The Generation R Study
}

\author{
Büşra Durmuş $\cdot$ Lamise Ay $\cdot$ Anita C. S. Hokken-Koelega • \\ Hein Raat • Albert Hofman • Eric A. P. Steegers • \\ Vincent W. V. Jaddoe
}

Received: 16 August 2010/Accepted: 27 December 2010/Published online: 13 January 2011

(C) The Author(s) 2011. This article is published with open access at Springerlink.com

\begin{abstract}
Maternal smoking during pregnancy increases the risk of obesity in the offspring. Not much is known about the associations with other measures of body composition. We assessed the associations of maternal smoking during pregnancy with the development of subcutaneous fat mass measured as peripheral and central skinfold thickness measurements in early childhood, in a population-based prospective cohort study from early fetal life onward in the city of Rotterdam, The Netherlands. The study was performed in 907 mothers and their children at the ages of 1.5, 6 and 24 months. As compared to nonsmoking mothers, mothers who continued smoking during pregnancy were more likely to have a younger age and a lower educational level. Their children had a lower birth
\end{abstract}

B. Durmuş $\cdot$ L. Ay · V. W. V. Jaddoe $(\bowtie)$

The Generation R Study Group (AE-006), Erasmus Medical Center, PO Box 2040, 3000, CA, Rotterdam, The Netherlands e-mail: v.jaddoe@erasmusmc.nl

B. Durmuş · L. Ay · V. W. V. Jaddoe

Department of Pediatrics, Erasmus Medical Center, Rotterdam,

The Netherlands

B. Durmuş · L. Ay · A. Hofman · V. W. V. Jaddoe Department of Epidemiology, Erasmus Medical Center, Rotterdam, The Netherlands

A. C. S. Hokken-Koelega

Department of Pediatrics, Subdivision of Endocrinology,

Erasmus Medical Center, Rotterdam, The Netherlands

H. Raat

Department of Public Health, Erasmus Medical Center,

Rotterdam, The Netherlands

E. A. P. Steegers

Department of Obstetrics and Gynecology, Erasmus Medical Center, Rotterdam, The Netherlands weight, higher risk of small size for gestational age and were breastfed for a shorter duration $(P$-values $<0.01)$. We did not observe differences in peripheral, central and total subcutaneous fat mass between the offspring of nonsmoking mothers, mothers who smoked in first trimester only and mothers who continued smoking during pregnancy $(P>0.05)$. Also, the reported number of cigarettes smoked by mothers in both first and third trimester of pregnancy were not associated with peripheral, central and total subcutaneous fat mass in the offspring at the ages of 1.5, 6 and 24 months. Our findings suggest that fetal exposure to cigarette smoke during pregnancy does not influence subcutaneous fat mass in early childhood. Follow-up studies are needed in children at older ages and to identify associations of maternal smoking during pregnancy with other measures of body composition.

Keywords Body composition - Cohort - Maternal smoking $\cdot$ Obesity $\cdot$ Paediatrics $\cdot$ Skinfold

$\begin{array}{ll}\text { Abbreviations } \\ \text { SFT } & \text { Skinfold thickness } \\ \text { ICC } & \text { Intraclass correlation coefficient } \\ \text { CI } & \text { Confidence interval } \\ \text { DXA } & \text { Dual Energy X-ray Absorptiometry } \\ \text { SD } & \text { Standard deviation }\end{array}$

\section{Introduction}

Active maternal smoking during pregnancy is a common and preventable specific adverse environmental exposure for the fetus [1-3]. Maternal smoking during pregnancy is associated with fetal growth retardation and increased risks 
of preterm birth and lower birth weight [4-6]. Maternal smoking during pregnancy also seems to increase the risk of obesity in the offspring [7,8]. The mechanisms underlying these associations may include developmental adaptations leading to changes in body composition and appetite behaviour [9, 10]. A recent systematic review suggested that prenatal smoke exposure leads to a higher body mass index in childhood [11]. However, using body mass index as outcome does not give information about body composition [12, 13]. Studies relating maternal smoking during pregnancy with direct measures of body composition in the offspring might be important since adverse body composition and especially unfavourable fat distribution are important contributors to metabolic syndrome outcomes [14]. Thus far, studies on the association between maternal smoking during pregnancy and measures of body composition are scarce and showed inconsistent results [15-17]. Skinfold thickness is a valid and easy to perform measurement for subcutaneous fat mass assessment in young children in epidemiological studies [12, 13].

For the present study, we hypothesized that active maternal smoking during pregnancy leads to higher peripheral, central and total subcutaneous fat mass in young childhood. We examined in a population-based prospective cohort study among 907 Dutch mothers and children followed from early fetal life onwards, the associations of exposure to maternal smoking during pregnancy with peripheral, central and total subcutaneous fat mass at the ages of 1.5, 6 and 24 months.

\section{Methods}

Design

This study was embedded in the Generation R Study, a population-based prospective cohort study of pregnant women and their children from fetal life onwards in Rotterdam, the Netherlands [18, 19]. Enrolment in the study was aimed at early pregnancy (gestational age $<18$ weeks) but was possible until birth of the child. All children were born between April 2002 and January 2006, and form a prenatally enrolled birth-cohort that is currently followed until young adulthood. Of all eligible children in the study area, $61 \%$ were participating in the study at birth [19]. Additional detailed assessments of fetal and postnatal growth and development were conducted in third trimester of pregnancy in a subgroup of 1,232 Dutch mothers and their children in order to exclude bias due to ethnicity [19]. Dutch ethnicity was defined as having two parents and four grandparents born in the Netherlands [19, 20]. Pregnant mothers participating in the Generation R study, who met this criterion, were approached for the additional measurements $[18,19]$. Of all approached women, $80 \%$ agreed to participate in the subgroup study. In total, 1,039 children participated in at least one of the postnatal assessments at the ages of 1.5, 6 and 24 months. The study protocol was approved by the Medical Ethical Committee of the Erasmus Medical Centre, Rotterdam. Written informed consent was obtained from all participants or their parents.

\section{Data collection and measurements}

\section{Maternal smoking during pregnancy}

Information about maternal smoking was obtained by postal questionnaires sent in first, second and third trimester of pregnancy. Response rates for these questionnaires were 91, 80 , and $77 \%$, respectively [19]. Active maternal smoking at enrolment was assessed in the first questionnaire by asking the mother whether she smoked during her pregnancy. We grouped mothers into three categories: (1) never smoked; (2) smoked only until their pregnancy was acknowledged (first trimester only); and (3) continued to smoke during pregnancy. This first questionnaire was sent to all mothers, independently of gestational age at enrolment. In the second and third questionnaires, the mothers were asked whether they had smoked during the past 2 months (yes/no). Mothers who reported in the first questionnaire not to smoke or to have smoked until their pregnancy was acknowledged, but reported to have smoked in the second or third questionnaire were recategorized as "continued smoking". Among smokers, the number of cigarettes daily smoked was categorized into the categories: no smoking, $<5$ cigarettes/ day and $>5$ cigarettes/day.

Subcutaneous fat mass measurements and anthropometrics

Subcutaneous fat mass was measured as skinfold thickness (SFT) at the ages of 1.5, 6 and 24 months on the left side of the body at four different sites (biceps, triceps, suprailiacal and subscapular) according to standard procedures by using a skinfold calliper (Slim Guide, Creative Health Products) [21]. Four well-trained medical assistants performed all measurements [22]. The consensus between and among observers for the medical assistants was analysed using the intraclass correlation coefficient (ICC) [23, 24]. Intraobserver ICC was 0.88 and interobserver ICC was 0.76 . Total subcutaneous fat mass was calculated from the sum of biceps SFT + triceps SFT + suprailiacal SFT + subscapular SFT. Central subcutaneous fat mass was calculated from the sum of suprailiacal SFT + subscapular SFT. Peripheral subcutaneous fat mass was calculated from the 
sum of biceps SFT + triceps SFT $[25,26]$. Body length was measured in supine position to the nearest millimeter using a neonatometer and at the age of 24 months, height was measured by a Harpenden stadiometer (Holtain Limited, Dyfed, UK) in standing position. Weight was measured in naked infants to the nearest grams at the ages of 1.5 and 6 months by an electronic infant scale (SECA) and at the age of 24 months by a mechanical personal scale (SECA).

\section{Covariates}

Birth weight, date of birth and sex were obtained from midwife and hospital registries at birth. Information about highest attained maternal educational level (low, moderate and higher), and parity (primipara, multipara) were obtained at enrolment in the study [27]. Educational level of the mother was defined according to the classification of Statistics Netherlands [28]. Maternal height and weight were assessed at enrolment. Height and weight were measured while the mother stood without shoes and without heavy clothing. Body mass index was calculated $\left(\mathrm{kg} / \mathrm{m}^{2}\right)$. Information on breastfeeding (yes/no) was obtained by postnatal questionnaires at the ages of 2, 6 , and 12 months. Mothers were asked whether they ever breastfed their child (yes/no) and at what age they quitted breastfeeding.

\section{Population for analysis}

From the total of 1,106 children and their mothers who gave consent for participating in the postnatal phase, 1,039 children participated in at least one of the postnatal assessments at the ages of 1.5, 6 and 24 months (Fig. 1). Children without complete information on maternal smoking during pregnancy $(\mathrm{n}=111)$ were excluded from the analyses. Of the remaining 928 live births with complete data on maternal smoking, information about the sum of skinfold thickness measurements in at least one of the three visits was available in 907 children. Twins $(n=24)$ were not excluded from the analyses, as they did not differ in the outcome measure from the singletons and no differences in results were observed after excluding them. Missing skinfold measurements were mainly due to crying behaviour. Percentage of maternal smoking was not different between participating mothers $(n=907)$ and those lost to follow-up $(\mathrm{n}=325)$.

\section{Statistical analysis}

Differences in baseline characteristics between the maternal smoking categories were compared with Student's $t$ test for continuous variables and Chi-square tests for categorical variables. Similarly, we tested the differences in peripheral, central and total subcutaneous fat mass between the maternal smoking categories at the ages of 1.5, 6 and 24 months. The associations between period of maternal smoking during pregnancy (no, first trimester only, continued) and peripheral, central and total subcutaneous fat mass at the ages of 1.5, 6 and 24 months, were assessed using multiple linear regression models. The models were adjusted for potential confounders including child's age at visit, sex, maternal education, maternal height and weight, breastfeeding (yes/no), current height and observer of the skinfold measurement. Postnatal smoking, birth weight, parity, maternal alcohol use and maternal age were not included in the final models since they did not materially change the effect estimates. Similar regression models were used for assessing the associations of the reported number of cigarettes smoked in both first and third trimester of pregnancy and peripheral, central, and total subcutaneous fat mass. The associations between period of maternal smoking during pregnancy and anthropometrics like height, weight and body mass index at the ages of 1.5, 6 and 24 months, were also assessed using multiple linear regression models. These models were adjusted for potential confounders like age at visit, sex, maternal education, maternal height and weight, and breastfeeding (yes/no).

Tests for trends were performed by treating each categorized variable as a continuous term and by entering the variable into the fully adjusted linear regression model. To handle missing values in covariates $(<20 \%$ missing), we performed multiple imputations with a software package by generating 5 independent datasets for all analyses. Imputations were based on the relationships between all covariates included in this study using the Markov Chain Monte Carlo method. All measures of association are presented with their 95\% CI. Statistical analyses including the multiple imputations were performed using the Statistical Package of Social Sciences version 17.0 for Windows (SPSS Inc., Chicago, IL, USA).

\section{Results}

Of all mothers included in the analyses, 9.2\% $(\mathrm{n}=83)$ reported smoking in first trimester only and $13.8 \%$ $(\mathrm{n}=125)$ reported continued smoking during pregnancy (Table 1). Mothers who continued smoking were younger and lower educated than mothers who never smoked during pregnancy. Mean birth weights of children from mothers who never smoked during pregnancy and who continued smoking were 3,533 grams (SD 545) and 3,267 grams (SD 573), respectively. In children of mothers who continued smoking, the highest rate for small size for gestational age $(14.4 \%)$ and lowest rate for ever breastfeeding (82.5\%) were observed. As compared to mothers who did participate, those who did not participate were younger 


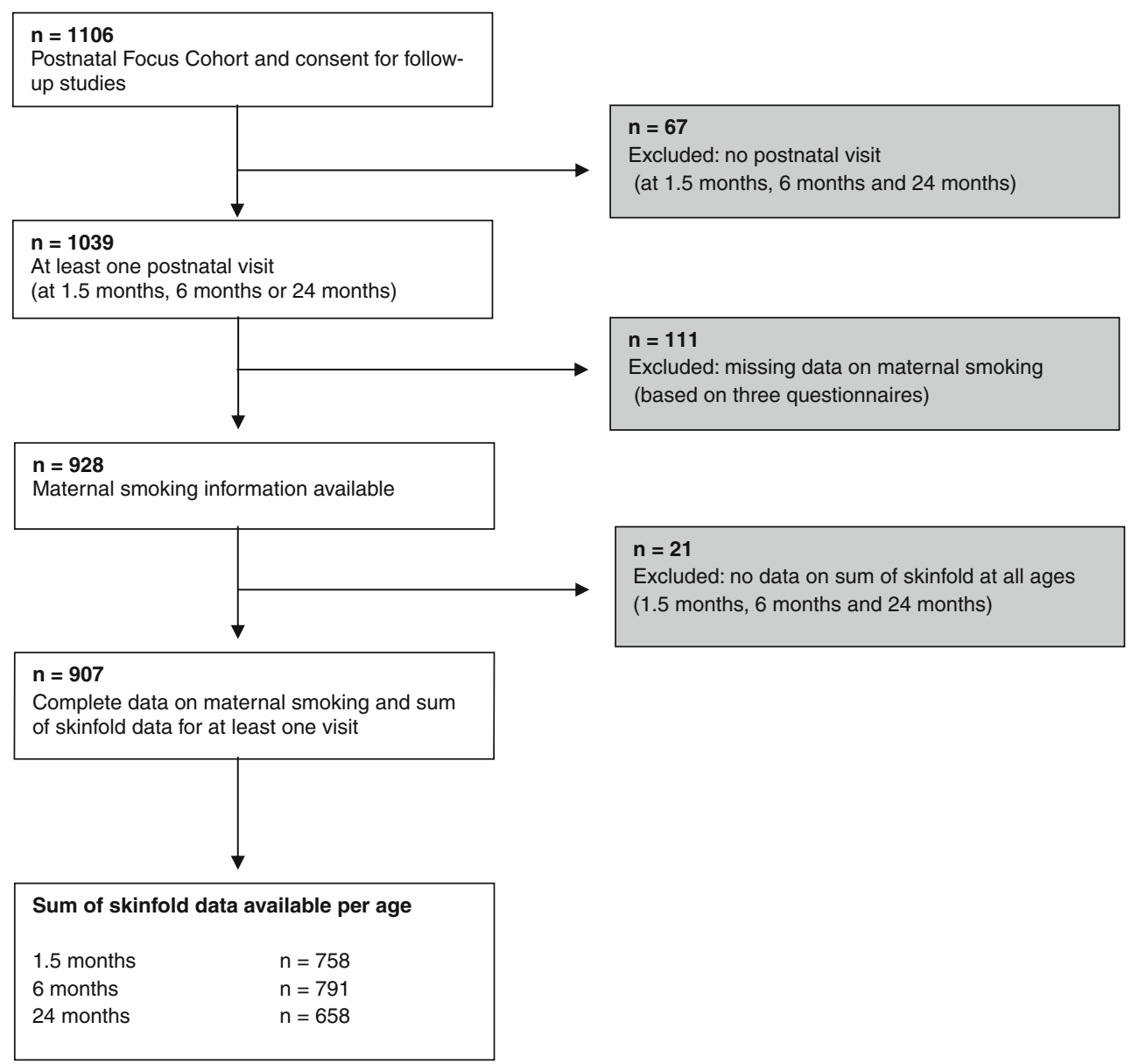

Fig. 1 Flow chart of participants in study

$(P<0.01)$. Furthermore, they had a lower educational level and were more likely to smoke $(P<0.01)$. Their children were also born more frequently preterm and with a lower birth weight $(P<0.05)$ (data not shown).

Table 2 shows that we observed no differences in the unadjusted peripheral, central and total subcutaneous fat mass measurements during childhood between the offspring of non-smoking mothers, mothers who smoked in first trimester and mothers who continued smoking. Table 3 gives the associations between period of maternal smoking, and the number of cigarettes smoked per day among mothers who smoked in first trimester only and those who continued smoking with peripheral, central and total subcutaneous fat mass at the ages of 1.5, 6 and 24 months. Smoking in first trimester only and continued smoking were not significantly associated with subcutaneous fat mass at any age. Offspring of mothers who continued to smoke more than 5 cigarettes per day tended to have higher peripheral, central and total subcutaneous fat mass at the age of 24 months ( $\mathrm{P}$ for trend $>0.05$ ). However, it is likely a chance finding given it didn't seem to be an a priori association from the methods and multiple comparisons. Table 4 shows the associations between period of maternal smoking, and the number of cigarettes smoked per day among mothers who smoked in first trimester only and those who continued smoking with height, weight and body mass index at the ages of 1.5, 6 and 24 months. Children of mothers who continued smoking tended to have a lower height and weight at all ages compared to non-smoking mothers. Offspring of mothers who smoked more than 5 cigarettes per day among those who smoked in first trimester only and those who continued smoking, tended to have a lower height and weight ( $P$ for trend $<0.10$ ). The association with body mass index at these ages seems not to be consistent, but tends to a negative relation with anthropometrics.

\section{Discussion}

Main findings

This population-based prospective cohort study showed that maternal smoking in first trimester only and continued 
Table 1 Characteristics of mothers and their children according to category of maternal smoking during pregnancy

\begin{tabular}{|c|c|c|c|}
\hline $\mathrm{N}=907$ & $\begin{array}{l}\text { No smoking } \\
(\mathrm{n}=699,77.1 \%)\end{array}$ & $\begin{array}{l}\text { Smoked in first trimester } \\
\text { only }(\mathrm{n}=83,9.2 \%)\end{array}$ & $\begin{array}{l}\text { Continued smoking } \\
(\mathrm{n}=125,13.8 \%)\end{array}$ \\
\hline \multicolumn{4}{|l|}{ Maternal characteristics } \\
\hline Age (years) & $31.9(25.3-37.8)$ & $31.2(22.1-38.4)$ & $30.8(21.5-38.0)^{* *}$ \\
\hline Height (cm) & $171.3(6.4)$ & $171.2(6.6)$ & $169.5(6.2)^{* *}$ \\
\hline Weight (kg) & $71.7(13.3)$ & $69.7(11.3)$ & $71.1(13.5)$ \\
\hline Body mass index $\left(\mathrm{kg} / \mathrm{m}^{2}\right)$ & $24.4(4.3)$ & $23.7(3.4)$ & $24.7(4.5)$ \\
\hline \multicolumn{4}{|l|}{ Highest completed education (\%) } \\
\hline Primary school & 1.0 & 4.9 & $6.4 * *$ \\
\hline Secondary school & 30.7 & 34.9 & $57.6^{* *}$ \\
\hline Higher education & 68.3 & 60.2 & $36.0 * *$ \\
\hline \multicolumn{4}{|c|}{ Alcohol consumption in pregnancy $(\%)$} \\
\hline Ever & 69.0 & $85.5 * *$ & 68.0 \\
\hline Never & 31.0 & $14.5 * *$ & 31.0 \\
\hline \multicolumn{4}{|l|}{ Parity $(\%)$} \\
\hline 0 & 60.9 & 71.1 & 57.6 \\
\hline$>=1$ & 39.1 & 28.9 & 42.4 \\
\hline \multicolumn{4}{|l|}{ Birth } \\
\hline Males (\%) & 51 & 46 & $58 *$ \\
\hline Gestational age (weeks) & $40.0(37.0-42.1)$ & $39.7(33.9-42.0)$ & $39.8(35.7-42.1)$ \\
\hline Weight (grams) & $3,533(545)$ & $3,458(659)$ & $3,267(573)^{* *}$ \\
\hline Small for gestational age $(<5 \%)$ & 3.1 & 3.6 & $14.4 * *$ \\
\hline Low birth weight $(<2,500 \mathrm{~g}) \%$ & 3.9 & 8.4 & 7.2 \\
\hline Preterm birth $(\%)$ & 5.2 & 9.6 & 6.4 \\
\hline \multicolumn{4}{|l|}{ Breastfeeding } \\
\hline Ever $(\%)$ & 90.6 & 94.0 & $82.5^{* *}$ \\
\hline Duration (months) & $5.4(0.5-12.0)$ & $4.6(0.5-12.0)$ & $2.5(0.5-8.5)^{* *}$ \\
\hline
\end{tabular}

Values are means (SD), percentages or medians (90\% range) for variables with skewed distribution

Differences in maternal and child characteristics (compared with the nonsmoking category) were evaluated using Students $t$ test for continuous variables and chi-squared tests for categorical variables. Gestational age was log-transformed for the $t$ test. Birth weight in SDS was used for the $t$ test

Small for gestational age is defined as the lowest $5 \%$ of gestational age adjusted birth weight

$* P<0.05$ and $* * P<0.01$

smoking during pregnancy were not associated with peripheral, central and total subcutaneous fat mass at the ages of $1.5,6$ and 24 months.

Strengths and weaknesses

Major strengths of this study are the population-based prospective design with subjects being studied from early pregnancy onwards, and information about a large number of potential confounders available. However, some methodological issues need to be considered. Of the 1,039 children of this study who participated postnatally, information about smoking during pregnancy at enrolment was missing in $11 \%$ of all mothers. This non-response would lead to biased effect estimates if the associations of maternal smoking during pregnancy with skinfold measurements in early childhood would be different between those included and not included in the analyses. However, this seems unlikely because biased estimates in cohort studies mainly arise from loss to follow-up rather than from non-response at baseline [29, 30]. The percentage of mothers who smoked during pregnancy may have been higher among those not included in the present analyses than among those who were included. This might have led to loss of statistical power and some under-estimation of the estimated effects. Of the postnatal participants, skinfold thickness measurements were performed in at least $80 \%$. Missing skinfold measurements were mainly due to crying behaviour. Information about maternal smoking during pregnancy was collected by questionnaires, without 
Table 2 Subcutaneous fat mass measurements according to maternal smoking during pregnancy category

\begin{tabular}{|c|c|c|c|}
\hline $\mathrm{N}=907$ & $\begin{array}{l}\text { No smoking } \\
(\mathrm{n}=699,77.1 \%)\end{array}$ & $\begin{array}{l}\text { Smoked in first trimester } \\
\text { only }(\mathrm{n}=83,9.2 \%)\end{array}$ & $\begin{array}{l}\text { Continued smoking } \\
(\mathrm{n}=125,13.8 \%)\end{array}$ \\
\hline \multicolumn{4}{|l|}{1.5 months $(\mathrm{n}=758)$} \\
\hline Age (months) & $1.60(1.12-2.47)$ & $1.59(1.08-2.49)$ & $1.63(1.03-2.66)$ \\
\hline Triceps (mm) & $6.6(4.0-12.0)$ & $6.5(4.0-12.0)$ & $6.6(3.5-12.0)$ \\
\hline Biceps (mm) & $5.5(3.0-11.0)$ & $5.5(3.0-10.0)$ & $5.6(3.0-10.0)$ \\
\hline Suprailiacal (mm) & $5.8(3.0-10.0)$ & $5.8(3.0-10.4)$ & $5.7(3.0-9.9)$ \\
\hline Subscapular (mm) & $6.2(4.0-9.6)$ & $6.3(4.0-10.0)$ & $6.1(3.0-9.0)$ \\
\hline Peripheral fat mass $(\mathrm{mm})$ & $12.2(7.0-22.2)$ & $12.0(7.0-22.3)$ & $12.2(7.0-21.0)$ \\
\hline Central fat mass $(\mathrm{mm})$ & $12.0(7.0-19.0)$ & $12.1(7.8-20.0)$ & $11.8(7.0-19.0)$ \\
\hline Total fat mass (mm) & $24.2(15.0-39.9)$ & $24.1(15.5-41.4)$ & $24.0(14.0-40.5)$ \\
\hline \multicolumn{4}{|l|}{6 months $(\mathrm{n}=791)$} \\
\hline Age (months) & $6.49(5.61-7.88)$ & $6.52(5.70-7.84)$ & $6.48(5.46-7.91)$ \\
\hline Triceps (mm) & $7.9(5.0-13.0)$ & $8.1(4.7-14.0)$ & $7.8(5.0-11.4)$ \\
\hline Biceps (mm) & $6.5(4.0-11.0)$ & $6.9(4.0-11.3)$ & $6.6(4.0-10.0)$ \\
\hline Suprailiacal (mm) & $6.3(3.5-10.0)$ & $6.7(3.5-9.3)$ & $6.1(3.1-9.8)$ \\
\hline Subscapular (mm) & $6.3(4.0-9.0)$ & $6.6(4.0-9.6)$ & $6.3(4.0-9.0)$ \\
\hline Peripheral fat mass (mm) & $14.5(9.0-22.0)$ & $14.9(9.0-25.3)$ & $14.4(9.1-21.0)$ \\
\hline Central fat mass $(\mathrm{mm})$ & $12.6(8.0-19.0)$ & $13.3(8.0-19.0)$ & $12.4(7.6-18.0)$ \\
\hline Total fat mass $(\mathrm{mm})$ & $27.1(19.0-39.0)$ & $28.2(17.0-43.3)$ & $26.8(17.1-37.4)$ \\
\hline \multicolumn{4}{|l|}{24 months $(\mathrm{n}=658)$} \\
\hline Age (months) & $25.29(23.79-27.61)$ & $25.45(23.92-29.16)$ & $25.51(23.95-28.04)$ \\
\hline Triceps (mm) & $8.8(5.0-14.0)$ & $8.7(4.0-13.3)$ & $9.0(5.0-13.9)$ \\
\hline Biceps (mm) & $6.7(4.0-11.0)$ & $6.6(3.4-11.7)$ & $6.9(4.0-11.0)$ \\
\hline Suprailiacal (mm) & $5.6(3.0-9.0)$ & $5.8(3.0-11.3)$ & $5.7(3.0-9.0)$ \\
\hline Subscapular (mm) & $6.0(3.5-9.0)$ & $6.2(4.0-10.0)$ & $6.3(4.0-9.8)$ \\
\hline Peripheral fat mass (mm) & $15.5(9.0-24.0)$ & $15.3(9.0-24.8)$ & $15.8(9.6-24.0)$ \\
\hline Central fat mass (mm) & $11.6(7.0-18.0)$ & $12.0(7.2-18.7)$ & $12.0(7.0-18.0)$ \\
\hline Total fat mass (mm) & $27.1(17.5-40.0)$ & $27.3(18.0-44.2)$ & $28.0(18.0-41.1)$ \\
\hline
\end{tabular}

Values are medians (90\% range). Differences in child characteristics (compared with the non-smoking category) were evaluated using Students $t$ test for continuous variables

Peripheral subcutaneous fat mass was calculated from the sum of biceps SFT + triceps SFT. Central subcutaneous fat mass was calculated from the sum of suprailiacal SFT + subscapular SFT. Total subcutaneous fat mass was calculated from the sum of biceps SFT + triceps SFT + suprailiacal SFT + subscapular SFT

reference to any skinfold measurement. Although assessing smoking during pregnancy by questionnaire seems to be a valid method, misclassification may occur [31]. Underreporting of maternal smoking across the various smoking categories may be present and have led to misclassification. In general, underreporting would lead to underestimation of differences between children from smoking and nonsmoking mothers. Also, our study group was ethnic homogeneous and the mothers were highly educated. This may limit the generalizability of our results [30]. Finally, we used skinfold thickness as a measure of subcutaneous fat mass. Skinfold thickness provides a simple, easy, and quick yet highly informative assessment of regional fatness in most age groups and can be used in large-scale epidemiological studies, but has a limitation in differentiating between lean and fat mass of the whole body [12].

Comparison of main findings with other studies

Obesity in both childhood and adulthood lead to different risk factors for cardiovascular diseases, diabetes type II and overall mortality [32-43].

Various studies suggest that exposure to maternal smoking during fetal life leads to overweight and obesity in childhood. A systematic review by Oken suggested that prenatal maternal smoking exposure leads to a 50\% increased risk of overweight in childhood at the ages of 3-33 years [11]. Also, a recent meta-analysis using 17 


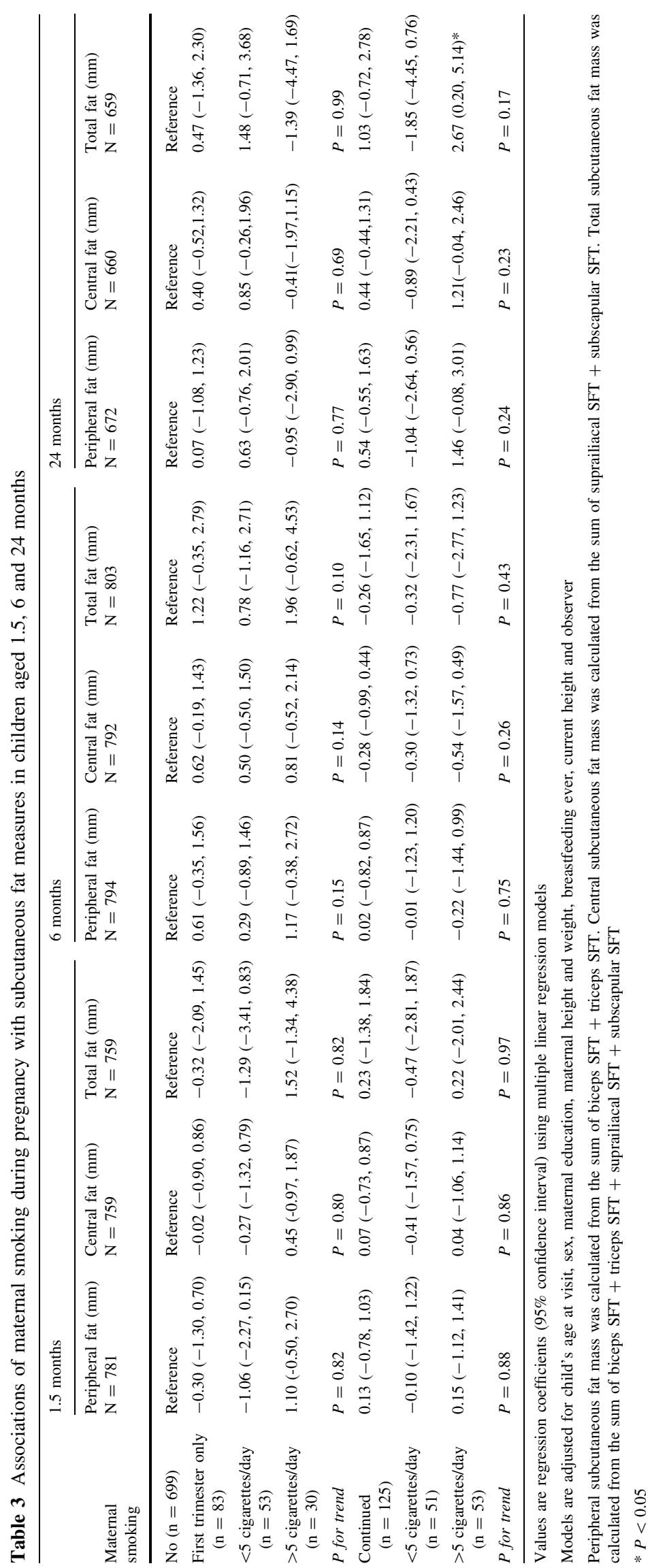




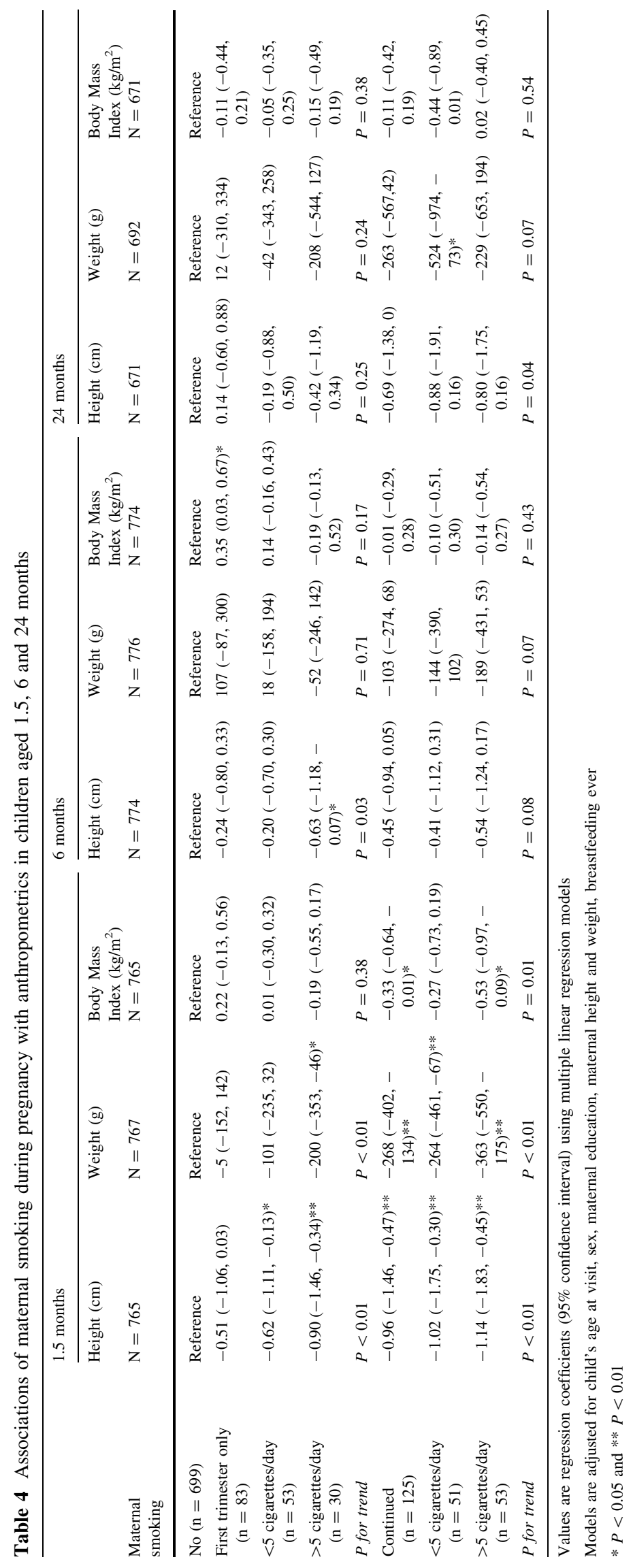


studies showed that maternal smoking during pregnancy was consistently associated with obesity in children with a mean age of 9 years [8]. It has been suggested that there is a dose-response association between the number of smoked cigarettes and the risk of childhood obesity [44]. These studies used body mass index as measure for childhood obesity. Using body mass index does not provide information about fat distribution [12]. A limited number of studies focused on the associations of maternal smoking during pregnancy with direct measures of body composition instead of body mass index. A study in Southampton showed in 448 neonates that maternal smoking in late pregnancy was weakly associated with a lower fat mass percentage and greater lean mass percentage [45]. Another study in Sweden and Norway observed in 315 children aged 5 years that maternal smoking was associated with an increased risk of skinfold thickness higher than the 85th percentile, however the associations attenuated after adjustment for confounders like total energy intake of the parents [17]. In contrast, a study in Boston, among 746 children at the age of 3 years, showed no association of maternal smoking during pregnancy with central adiposity, measured by the subscapular and triceps ratio, which has been found to be a valid proxy for intra-abdominal adipose tissue among children [15].

A study in Bristol, the United Kingdom found in 5,689 children with mean age of 10 years that maternal smoking at any time during pregnancy is associated with higher offspring total fat mass measured with Dual X-ray Absorptiometry (DXA). Maternal smoking was also associated with higher lean mass, but to a lesser extent [16]. In our study, we used skinfold thickness as measure of subcutaneous fat mass at the ages of 1.5, 6 and 24 months. We did not find significant associations between maternal smoking during pregnancy and peripheral, central and total subcutaneous fat mass in early childhood. We also did not observe associations between the number of cigarettes smoked during pregnancy and peripheral, central and total subcutaneous fat mass in the offspring. Most previous studies assessed the associations between maternal smoking and adiposity at older age. The lack of association in this study might be due to the younger age groups, or use less advanced measuring techniques. This might also be the explanation for the inconsistent associations between maternal smoking during pregnancy and body mass index. In the future, genome wide association studies might identify new genetic loci related to skinfold thickness [46].

Studies examining the influence of prenatal smoke exposure in different periods of pregnancy might identify critical time periods, which are important from both a developmental and preventive perspective. We showed that both maternal first trimester smoking and continued smoking were not associated with peripheral, central and total subcutaneous fat mass until the age of 2 years.

\section{Conclusion}

Our findings suggest that intrauterine exposure to maternal cigarette smoke in different periods during pregnancy does not influence peripheral, central and total subcutaneous fat mass development in early childhood. Further studies are needed in children at older ages and to identify associations of maternal smoking during pregnancy with other measures of body composition like DXA and Magnetic Resonance Imaging.

Acknowledgments The Generation R Study is conducted by the Erasmus Medical Center in close collaboration with the School of Law and Faculty of Social Sciences of the Erasmus University Rotterdam, the Municipal Health Service Rotterdam area, Rotterdam, the Rotterdam Homecare Foundation, Rotterdam and the Stichting Trombosedienst and Artsenlaboratorium Rijnmond (STAR), Rotterdam. We gratefully acknowledge the contribution of participating mothers, general practitioners, hospitals, midwives and pharmacies in Rotterdam. The first phase of the Generation R Study is made possible by financial support from the Erasmus Medical Center, Rotterdam, the Erasmus University Rotterdam and the Netherlands Organization for Health Research and Development. The researchers are independent from the funders. The study sponsors had no role in study design, data analysis, interpretation of data, or writing this report. Vincent Jaddoe received an additional grant from the Netherlands Organization for Health Research and Development (ZonMw 90700303, 916.10159). Financial support was obtained from Danone.

Conflict of interests None to declare.

Open Access This article is distributed under the terms of the Creative Commons Attribution Noncommercial License which permits any noncommercial use, distribution, and reproduction in any medium, provided the original author(s) and source are credited.

\section{References}

1. Kramer MS. Determinants of low birth weight: methodological assessment and meta-analysis. Bull WHO. 1987;65:663-737.

2. Abel EL. Smoking during pregnancy: a review of effects on growth and development of offspring. Hum Biol. 1980;52:593625.

3. Neovius K, Rasmussen F, Sundström J, Neovius M. Forecast of future premature mortality as a result of trends in obesity and smoking: nationwide cohort simulation study. Eur J Epidemiol. 2010;10:703-9.

4. Cnattingius S. The epidemiology of smoking during pregnancy: smoking prevalence, maternal characteristics, and pregnancy outcomes. Nicotine Tob Res. 2004;6:125-40.

5. Andres RL. Perinatal complications associated with maternal smoking. Semin Neonatol. 2005;5:231-41.

6. Castles A, Adams EK, Melvin CL, Kelsch C, Boulton ML. Effects of smoking during pregnancy. Five meta-analyses. Am J Prev Med. 1999;16: 208-15. 
7. von-Kries R, Toschke AM, Kolezko B, Slikker W Jr. Maternal smoking during pregnancy and childhood obesity. Am J Epidemiol. 2002;156:954-61.

8. Ino T. Maternal smoking during pregnancy and offspring obesity: meta-analysis. Pediatr Int. 2010;52:94-9.

9. Barker DJ. Fetal origins of coronary heart disease. BMJ. 1995; 311:171-4.

10. Bateson P, Barker D, Clutton-Brock T, Deb D, D'Udine B, Foley RA, et al. Developmental plasticity and human health. Nature. 2004;430:419-21.

11. Oken E, Levitan EB, Gillman MW. Maternal smoking during pregnancy and child overweight: systematic review and metaanalysis. Int J Obes. 2008;32:201-10.

12. Wells JC, Fewtrell MS. Measuring body composition. Arch Dis Child. 2006;7:612-7.

13. Nevill AM, Stewart AD, Olds T, Holder R. Relationship between adiposity and body size reveals limitations of BMI. Am J Phys Anthropol. 2006;1:151-6.

14. Holzhauer S, Zwijsen RM, Jaddoe VW, Boehm G, Moll HA, Mulder PG, et al. Sonographic assessment of abdominal fat distribution in infancy. Eur J Epidemiol. 2009;24(9):521-9.

15. Oken E, Huh SY, Taveras EM, Rich-Edwards JW, Gillman MW. Associations of maternal prenatal smoking with child adiposity and blood pressure. Obesity Res. 2005;11:2021-8.

16. Leary SD, Smith GD, Rogers IS, Reilly JJ, Wells JC, Ness AR. Smoking during pregnancy and offspring fat and lean mass in childhood. Obesity. 2006;14:2284-93.

17. Widerøe M, Vik T, Jacobsen G, Bakketeig LS. Does maternal smoking during pregnancy cause childhood overweight? Paediatr Perinat Epidemiol. 2003;2:171-9.

18. Jaddoe VW, Bakker R, van Duijn CM, van der Heijden AJ, Lindemans J, Mackenbach JP, et al. The Generation R Study Biobank: a resource for epidemiological studies in children and their parents. Eur J Epidemiol. 2007;22:917-23.

19. Jaddoe VW, van Duijn CM, van der Heijden AJ, Mackenbach JP, Moll HA, Steegers EAP, et al. The Generation R Study: design and cohort update 2010. Eur J Epidemiol. 2010;11:823-41.

20. Allochtonen in Nederland 2004. Voorburg/Heerlen: Statistics Netherlands; 2004

21. Lohman TG, Roche AF, Martorell R. Anthropometric Standardization Reference Manual: Abridged Edition. Champaign, IL: Human Kinetics Books; 1991.

22. WHO Multicentre Growth Reference Study Group. Reliability of anthropometric measurements in the WHO Multicentre Growth Reference Study. Acta Paediatr. 2006;450:38-46.

23. Bland JM, Altman DG. Statistical methods for assessing agreement between two methods of clinical measurement. Lancet. 1986;8476:307-10.

24. Shrout PE, Fleiss JL. Intraclass correlations: uses in assessing rater reliability. Psychol Bull. 1979;2:420-8.

25. Ketel IJ, Volman MN, Seidell JC, Stehouwer CD, Twisk JW, Lambalk CB. Superiority of skinfold measurements and waist over waist-to-hip ratio for determination of body fat distribution in a population-based cohort of Caucasian Dutch adults. Eur J Endocrinol. 2007;6:655-61.

26. Birmingham B, Dyer AR, Shekelle RB, Stamler J. Subscapular and triceps skinfold thicknesses, body mass index and cardiovascular risk factors in a cohort of middle-aged employed men. J Clin Epidemiol. 1993;3:289-302.

27. Walter S, Tiemeier H. Variable selection: current practice in epidemiological studies. Eur J Epidemiol. 2009;12:733-6.

28. Standaard onderwijsindeling 2003. Voorburg/Heerlen: Statistics Netherlands; 2004.

29. Nohr EA, Frydenberg M, Henriksen TB, Olsen J. Does low participation in cohort studies induce bias? Epidemiol. 2006; 17:413-8.
30. Jacobsen TN, Nohr EA, Frydenberg M. Selection by socioeconomic factors into the Danish National Birth Cohort. Eur J Epidemiol. 2010;5:349-55.

31. Klebanoff MA, Levine RJ, Morris CD, Hauth JC, Sibai BM, Ben Curet L, et al. Accuracy of self-reported cigarette smoking among pregnant women in the 1990s. Paediatr Perinat Epidemiol. $2001 ; 15: 140-3$.

32. Osler M, Lund R, Kriegbaum M, Andersen AM. The influence of birth weight and body mass in early adulthood on early coronary heart disease risk among Danish men born in 1953. Eur J Epidemiol. 2009;1:57-61.

33. Setia MS, Quesnel-Vallee A, Abrahamowicz M, Tousignant P, Lynch J. Convergence of body mass index of immigrants to the Canadian-born population: evidence from the National Population Health Survey (1994-2006). Eur J Epidemiol. 2009;10: 611-23.

34. Nguyen QM, Srinivasan SR, Xu JH, Chen W, Berenson GS. Influence of childhood parental history of type 2 diabetes on the pre-diabetic and diabetic status in adulthood: the Bogalusa Heart Study. Eur J Epidemiol. 2009;9:537-9.

35. Sabanayagam C, Shankar A, Li J, Pollard C, Ducatman A. Serum gamma-glutamyl transferase level and diabetes mellitus among US adults. Eur J Epidemiol. 2009;7:369-73.

36. Olafsdottir E, Aspelund T, Sigurdsson G, Thorsson B, Benediktsson R, Harris TB, et al. Unfavourable risk factors for type 2 diabetes mellitus are already apparent more than a decade before onset in a population-based study of older persons: from the Age, Gene/Environment Susceptibility-Reykjavik Study (AGES-Reykjavik). Eur J Epidemiol. 2009;6:307-14.

37. Pires de Sousa AG, Pereira AC, Marquezine GF, Marques do Nascimento-Neto R, Freitas SN, de Nicolato RLC, et al. Derivation and external validation of a simple prediction model for the diagnosis of type 2 diabetes mellitus in the Brazilian urban population. Eur J Epidemiol. 2009;2:101-9.

38. Corpeleijn E, Bakker SJ, Stolk RP. Obesity and impaired renal function: potential for lifestyle intervention? Eur J Epidemiol. 2009;6:275-80.

39. Klenk J, Nagel G, Ulmer H, Strasak A, Concin H, Diem G, et al. Body mass index and mortality: results of a cohort of 184, 697 adults in Austria. Eur J Epidemiol. 2009;2:83-91.

40. Khashan AS, Kenny LC. The effects of maternal body mass index on pregnancy outcome. Eur J Epidemiol. 2009;11:697-705.

41. Rzehak P, Sausenthaler S, Koletzko S, Bauer CP, Schaaf B, von Berg A, et al. Period-specific growth, overweight and modification by breastfeeding in the GINI and LISA birth cohorts up to age 6 years. Eur J Epidemiol. 2009;8:449-67.

42. Pearce MS, Relton CL, Parker L, Unwin NC. Sex differences in the association between infant feeding and blood cholesterol in later life: the Newcastle thousand families cohort study at age 49-51 years. Eur J Epidemiol. 2009;7:375-80.

43. Balk L, Hoekstra T, Twisk J. Relationship between long-term coffee consumption and components of the metabolic syndrome: the Amsterdam Growth and Health Longitudinal Study. Eur J Epidemiol. 2009;4:203-9.

44. Suzuki K, Ando D, Sato M, Tanaka T, Kondo N, Yamagata Z. The association between maternal smoking during pregnancy and childhood obesity persists to the age of 9-10 years. J Epidemiol. 2009;3:136-42.

45. Harvey NC, Poole JR, Javaid MK, Dennison EM, Robinson S, Inskip HM. SWS study group. Parental determinants of neonatal body composition. J Clin Endocrinol Metab. 2007;2:523-6.

46. Psaty BM, Hofman A. Genome-wide association studies and large-scale collaborations in epidemiology. Eur J Epidemiol. 2010;8:525-9. 